\title{
Electron Cyclotron Resonance Heating for W7-X
}

\author{
G. Michel*, P. Brand ${ }^{\dagger}$, H. Braune*, V. Erckmann*, G. Gantenbein**, \\ W. Kasparek ${ }^{\dagger}$, H.P. Laqua*, N. Marushchenko*, J.W. Oosterbeek*, \\ M. Thumm** and M. Weißgerber ${ }^{*}$ \\ *Max-Planck-Institut für Plasmaphysik, TI Greifswald, EURATOM Ass., Greifswald, Germany \\ ${ }^{\dagger}$ Institut für Plasmaforschung, Universität Stuttgart, Stuttgart, Germany \\ ** Forschungszentrum Karlsruhe, EURATOM Ass., IHM, Karlsruhe, Germany \\ ${ }^{\ddagger}$ Max-Planck-Institut für Plasmaphysik, EURATOM Ass., Garching, Germany
}

\begin{abstract}
The HELIAS-type Stellarator Wendelstein 7-X, which is currently under construction in Greifswald, Germany, will be equipped with a $140 \mathrm{GHz}, 10 \mathrm{MW}$, CW ECRH system. It will be the main plasma heating system for W7-X. The key features and capabilities of the ECRH plant will be discussed together with the envisaged start-up and heating scenarios. We also report on the ECRH stray radiation test facility MISTRAL and on the extension of the gyrotron frequency range.
\end{abstract}

Keywords: ECRH, Gyrotrons, Transmission Lines

PACS: $52.35 . \mathrm{Hr}, 52.35 . \mathrm{Qz}$

\section{INTRODUCTION}

$\mathrm{W} 7-\mathrm{X}$ is a low-magnetic-shear drift-optimized stellarator (major radius $5.5 \mathrm{~m}$, minor radius $0.55 \mathrm{~m}$ ), which is currently under construction in Greifswald, Germany [1]. Its aim is to demonstrate reactor relevant plasma parameters $\left(T_{e}=2-10 \mathrm{keV}, T_{i}=2-\right.$ $5 \mathrm{keV}, n_{e}=0.1-3 \cdot 10^{20} \mathrm{~m}^{3}$ ) and a high relative plasma pressure $\beta$ of up to $5 \%$ under steady state conditions.

A CW ECRH power of $10 \mathrm{MW}$ at $140 \mathrm{GHz}$ is required to achieve these parameters [2]. In the first two years of operation, W7-X will be equipped with a ballistically cooled test divertor unit, which allows for $10 \mathrm{~s}$ pulses at $8 \mathrm{MW}$.

The ECRH plant consists of 10 independent gyrotron modules with an output capability of $1 \mathrm{MW}$ each. They are independent with respect to the cooling, the control and the power supplies. However, during the employment of the test divertor unit in W7-X the power supplies will only suffice to feed 8 gyrotrons. The RF power is transmitted by a purely quasi-optical multi-beam transmission line [2]. It is characterized by extraordinarily low mode conversion and transmission losses [3]. Figure 1 shows an overall sketch of the ECRH plant including cooling and power supplies.

\section{GYROTRON OPERATION AT A SECOND FREQUENCY}

The W7-X gyrotrons [4] are designed to produce the $140 \mathrm{GHz}$ millimeter waves in the $\mathrm{TE}_{28,8}$ cavity mode. This is the second harmonic of the electron cyclotron frequency in $\mathrm{W} 7-\mathrm{X}$ at a magnetic field of $2.5 \mathrm{~T}$. However, it is desirable to have a lower frequency available for physics investigations at reduced magnetic field, e.g. for high $\beta$ operation 


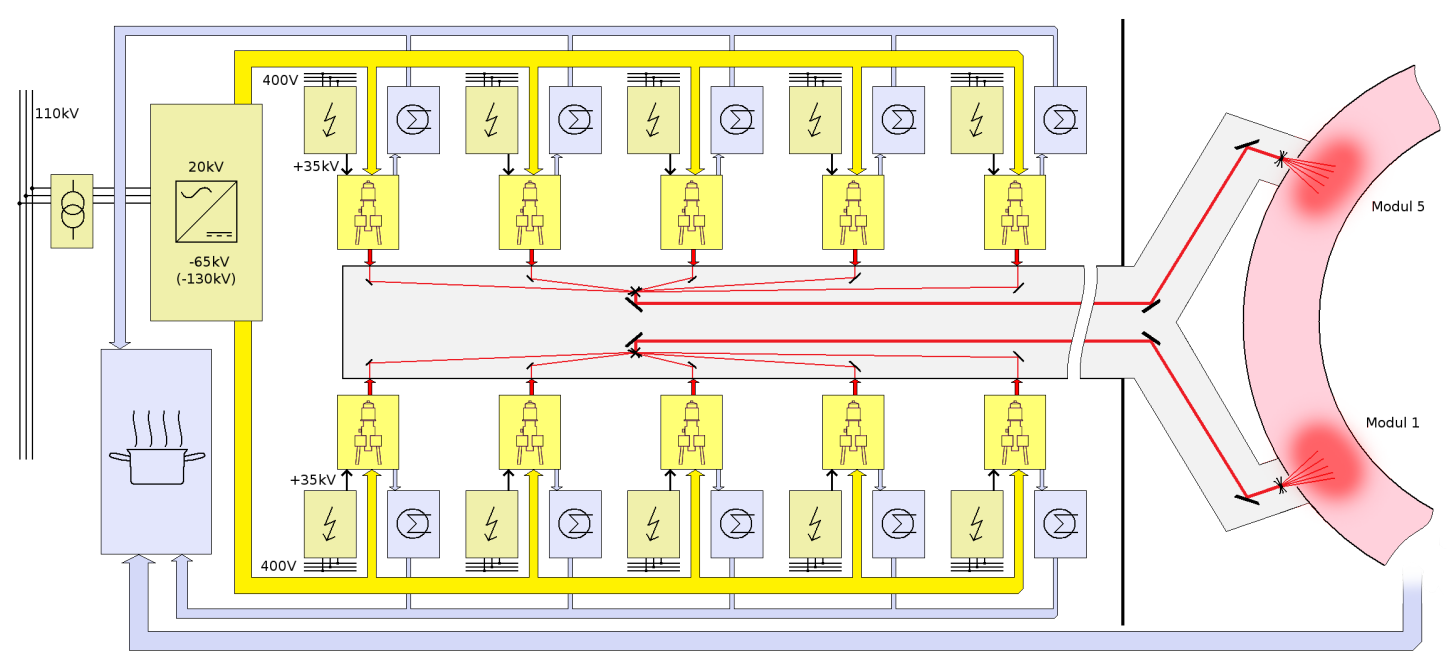

FIGURE 1. Overview of the ECRH system

(W7-X goal) or 3rd harmonic interaction at $140 \mathrm{GHz}$ which would need the second harmonic at $93.3 \mathrm{GHz}$ to produce a sufficiently hot target plasma.

It is possible to operate the gyrotron at a lower frequency (i.e. lower magnetic field) provided that the cavity mode has a similar caustic radius to achieve a sufficient interaction with the electron beam. The similar caustic radius and in addition a similar Brillouin angle at the taper output are also important for an efficient conversion by the quasi-optical mode converter in the gyrotron. Finally the output window of the gyrotron (which can be seen as a Fabry-Perot Resonator) must be transparent for the second frequency. All of these conditions are fulfilled by the $\mathrm{TE}_{21,6}$ mode which oscillates at $103.8 \mathrm{GHz}$. With that mode we have achieved an output power of $370 \mathrm{~kW}$ at $10 \mathrm{~s}$ or $525 \mathrm{~kW}$ at $5 \mathrm{~ms}$. The limitation of the power lies in the collector loading. In total, a power of $4 \mathrm{MW}$ will be available at $103.8 \mathrm{GHz}$.

The transmission line is of confocal design which means that the imaging properties are independent of the frequency over a wide range. Therefore the $103.8 \mathrm{GHz}$ beams can be transmitted to the plasma with the present transmission line. Due to the finite mirror size the transmission losses are only slightly higher compared to $140 \mathrm{GHz}$.

It would even be possible to operate the gyrotron at a higher frequency in the same manner [5], but this would require a stronger grotron magnet.

\section{IN-VESSEL COMPONENTS AND HEATING SCENARIOS}

The ECRH system at $\mathrm{W} 7-\mathrm{X}$ is designed with maximum flexibility in mind. Beyond plasma heating in the standard X2 and $\mathrm{O} 2$ schemes, it allows for high-field-side injection, beam launching along $|\mathbf{B}| \approx$ const surfaces as well as probe beam for collective Thomson scattering and it is the only source for non-inductive current drive as W7-X has no ohmic transformer. The latter is of major importance in order to compensate the bootstrap current and to shape the rotational transform $l$ on a shorter timescale such that 


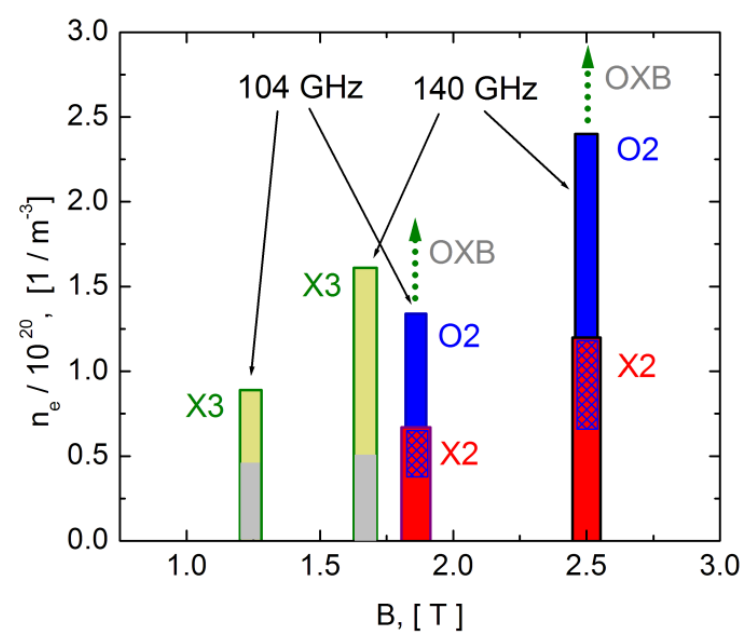

FIGURE 2. Accessible density range depending on the magnetic field

it fits the needs of a proper divertor operation. On larger timescales this can be achieved with external coils.

The accessible density range for both frequencies depending on the magnetic field is sketched in Figure 2. Electron temperatures above $6 \mathrm{keV}$ are expected for the standard $\mathrm{O} 2$ scenario [6] at $140 \mathrm{GHz}$. The target plasma for the $\mathrm{X} 3$ scenario at $140 \mathrm{GHz}, 1.66 \mathrm{~T}$ can possibly be produced with the help of $103.8 \mathrm{GHz}$ X2 injection.

Above the O2-cutoff, mode conversion heating is foreseen via the O-X-B mode conversion process with no upper density limit (although there is a lower one) and a high current drive efficiency.

The aforementioned flexibility is achieved by a set of 12 front steering launchers in the bean shaped plasma cross section (maximum $|\mathbf{B}|$ ) and 2 remote-steering-launchers close to the triangular cross section. The latter can be used for high field side and $|\mathbf{B}| \approx$ const launch for investigations on phase space interaction as well as probe beams for collective Thomson scattering. The front steering launchers are the work horses of the ECRH for current drive and heating. As the single-pass absorption in the $\mathrm{O} 2$ mode can be less than $80 \%$, reflecting TZM tiles (titanium, zirconium, molybdenum alloy) are placed at the opposite wall to allow for multi-pass absorption. This material is a trade-off between a low atomic number and a high heat resistivity and microwave reflectivity. In addition, there are polarization-compensated pick-up probes integrated in the opposite wall to measure the transmission/absorption and to eventually fine-tune the polarization.

\section{THE “MISTRAL” FACILITY}

During ECRH operation there is always a risk of high stray radiation in the plasma vessel. The $\mathrm{O}-\mathrm{X}-\mathrm{B}$ process is very sensitive to the proper injection angle. In the $\mathrm{O} 2$ and $\mathrm{X} 3$ regimes there is low single-pass absorption and somtimes the polarization and/or the injection angle are simply not well tuned. Especially at the critical transition from X2 to $\mathrm{O} 2$ or from $\mathrm{O} 2$ to $\mathrm{O}-\mathrm{X}-\mathrm{B}$ heating, all in-vessel components must be able to withstand the 
microwave stray radiation. Therefore we built a MIcrowave STray RAdiation Loading (MISTRAL) test facility to assess all critical in-vessel components.

From power balance estimations we expect a stray radiation level of roughly $100 \mathrm{~kW} / \mathrm{m}^{2}$ in $\mathrm{W} 7-\mathrm{X}$. Again with power balance estimations, this stray radiation level is generated in the MISTRAL vacuum chamber by a proper pulse width modulation of one of our gyrotrons.

The diagnostics include sniffer probes to monitor the power flux density, a video camera, an infrared camera, thermocouples and a vacuum gauge. Installation of a mass spectrometer is planned. The timely evolution of pressure and temperature at critical locations is recorded.

\section{PROGRESS OF THE CONSTRUCTION}

The ECRH towers which contain the beam dividing optics of the two multi-beam waveguides and the input optics for the launchers are completed.

Two out of four front steering launcher assemblies ( 3 beams each) have been manufactured and undergo currently the vacuum and stray radiation tests in the MISTRAL facility.

The gyrotron inventory consists of one CPI gyrotron and two prototype as well as seven series gyrotrons from a TED/FZK/CRPP joint venture. One of the series gyrotrons has passed the acceptance test. Four additional series tubes have been manufactured and are currently in the phase of a redesign of the electron beam compression tunnel which has been identified as a source of spurious gyrotron-like oscillations [7].

\section{REFERENCES}

1. Erckmann, V., H.J. Hartfuß, M. Kick, H. Renner, J. Sapper, F. Schauer, E. Speth, F. Wesner, F. Wagner, M. Wanner, A. Weller, and H. Wobig,: The W7-X project: Scientific Basis and Technical Realization, Proc. 17th IEEE/NPSS Symposium on Fusion Engineering, San Diego, USA (1997). Ed. IEEE, Piscataway, NJ 1998, 40 - 48

2. Erckmann, V. et. al., Electron Cyclotron Heating for W7-X: Physics and Technology, Fusion Science and Technology, Vol. 52, No.2(2007), pp.291-312, Publisher City, 2000, pp. 212-213.

3. Empacher, L. and Kasparek, W., Analysis of a multiple-beam waveguide for free-space transmission of microwaves, IEEE Trans. Antennas Propagat., Vol. AP-49 (2001) 483-493

4. Thumm, M. et al., EU megawatt-class 140-GHz CW gyrotron, IEEE Trans. on Plasma Science, 35 (2007) 143-153

5. Kern, S., Theoretical Study of $174 \mathrm{GHz}$ Operation of the W7-X $1 \mathrm{MW}, 140 \mathrm{GHz}$ Gyrotron, 33rd International Conference on Infrared, Millimeter, and Terahertz Waves, September 15-19, 2008, Pasadena, USA

6. Turkin, Y., C.D. Beidler, V. Erckmann, H.P. Laqua, H. Maaßberg, N.B. Marushchenko and W7-X Team, ECRH and transport simulation for W7-X, 34th EPS Conf. on Plasma Phys., Warsaw, ECA Vol.31F, P-1.148 (2007)

7. Gantenbein, G. et al. Experimental Results of Series Gyrotrons for the Stellarator W7-X, 22nd IAEA Fusion Energy Conference, 13-18 October 2008, Geneva, Switzerland 